\title{
REPORT ON THE PARTICIPATION IN THE XXXII INTERNATIONAL SCIENTIFIC CONGRESS OF THE POLISH SOCIETY OF SPORTS MEDICINE, WROC ŁAW (POLAND), 12-13 OCTOBER 2017
}

\author{
Zdzisław KOBOS 1,2 \\ 1Cardinal Stefan Wyszynski University in Warsaw, Institute of Psychology, Warsaw, Poland \\ 2Aeromedical Board in Warsaw, Warsaw, Poland
}

Source of support: Own sources

Author's address: Z. Kobos, Cardinal Stefan Wyszynski University in Warsaw, Institute of Psychology, Wóycickiego 1/3 Street, building 14, 01-444 Warsaw, e-mail: z.kobos@uksw.edu.pl

On 12-14 October 2017, in the capital of Lower Silesia, the XXXII International Scientific Congress of the Polish Society of Sports Medicine took place. It was also an opportunity to celebrate the 80th anniversary of sports medicine in Poland under the slogan "Challenges for the future". Historical beginnings of the formalized organization of sports doctors in Poland date back to 10 February 1937, when the First Congress of Polish Sports Doctors took place, during which the organization was established under the name of the Association of Sports Doctors (Stowarzyszenie Lekarzy Sportowych). In 1961, at the 9th Congress of the Association of Sports Doctors, the name was changed to the Polish Society of Sports Medicine (Polskie Towarzystwo Medycyny Sportowej), so that it could be joined by doctors of other specialties, dealing with the field of science concerning physical culture and specialists of other disciplines of knowledge dealing with sport and physical activity.

This great anniversary of the esteemed Society was attended by many distinguished guests from Poland and abroad, representing Polish and international sports organizations and research institutes, as well as centres specializing in sports medicine counselling. The Congress was also attended by representatives of research institutions dealing with the care of athletes, as well as specialist medical centres, qualifying candidates for various sports disciplines. Moreover, during the Congress, 
presentations of medical equipment used for diagnostics and health rehabilitation of athletes were provided.

The scientific partners of the Congress were several scientific societies, including, among others: International Federation of Sports Medicine (FIMS), European Federation of Sports Medicine Association (EFSMA), Polish Arthroscopic Society, Polish Society for Obesity Research, Polish Society of Spine Surgery, Polish Society of Physiotherapy, Polish Society of Family Medicine, Polish Hyperbaric Medicine and Technology Society, Polish Muscles, Ligaments and Tendons Society, Łódź Branch of the Polish Genetic Society.

The jubilee Congress was also attended by representatives of the Polish Academy of Sciences. Thus, the Committee of Rehabilitation, Physical Education and Social Integration of the Polish Academy of Sciences was represented by its president - Prof. Krzysztof Klukowski, M.D., PhD. The patronage of the Congress was taken by the President of the Polish Society of Sports Medicine - Andrzej Bugajski, M.D., PhD and the Director of the Central Sports Medicine Center, Chairman of the Medical Committee of the Polish Olympic Committee -Hubert Krysztofiak, M.D., PhD.

The sessions of the Congress were a multidisciplinary meeting of doctors, rehabilitators, psychologists, representatives of science of nutrition and wellness, as well as trainers and coaches. After the official welcome of the guests and participants of the Congress, inaugural presentations of representatives of international sports organizations as well as artistic performances took place. The substantive part of the Congress consisted of lectures during specialist sessions, poster sessions and workshops presenting the aspects of practical care of athletes and physically active people, doing or engaged in recreational physical activity.

Foreign lecturers who came to Wrocław and spoke during plenary sessions included: Prof. Fabio Pigozzi - President International Federation of Sports Medicine FIMS, Dr Andre Debruyne President European Federation of Sports Medicine Associations EFSMA, Prof. Martial Saugy from the Center of Research \& Expertise in Anti-doping Sciences, University of Lausanne (Switzerland), Prof. Ulrich Schneider from the Centre for Regenerative Medicine, Tegernesee (Germany), Prof. Keiko Ikemoto from the Fukushima Medical University (Japan), Dr Zbigniew Brodziński from the Dubai Bone \& Joint Centre MBR University Medical Cluster (UAE), Dr William Galway from the Hospital for Special Surgery in New York (USA), Dr Helmut Diers - Visiting Professor from the Johannes Guten- berg University Mainz (Germany), University Medical Centre Department of Orthopedics and Orthopedic Surgery Biomechanics \& Motion Analysis.

In the next part of the Congress, papers during specialist sessions were delivered by representatives of Polish and foreign specialist medical centres and scientific centres: Poznan University of Physical Education, Eugeniusz Piasecki in Poznań, Jerzy Kukuczka Academy of Physical Education in Katowice, University of Physical Education in Warsaw, Gdańsk University of Physical Education and Sport, Jozef Pilsudski University of Physical Education in Warsaw Faculty in Biala Podlaska, University School of Physical Education in Wrocław, Central Sports Medicine Centre, MARKMED Rehabilitation Centre, Maria Sklodowska-Curie Institute - Oncology Centre in Warsaw, Centre of Rehabilitation and Medical Education in Wroclaw, Centre for Regenerative Medicine in Tegernsee (Germany), Paediatric Centre in Sosnowiec, Centre of Rehabilitation and Medical Education in Wroclaw, eMKa Med Medical Centre in Wroclaw, Regional Centre of Sports Medicine SPORTVITA in Bydgoszcz, Institute of Biomedical Engineering, Dresden University of Technology (Germany), Polish Institute of Sport in Warsaw, Mossakowski Medical Research Centre of the Polish Academy of Sciences in Warsaw, Department of Neurosurgery in Sosnowiec, St. Luke's Clinic in Bielsko-Biała, Ministry of Sport and Tourism of the Republic of Poland, Ministry of Health of the Republic of Poland, Józef Rusiecki Olsztyn University College, Wiktor Dega Orthopaedic and Rehabilitation Clinical Hospital in Poznan, University of Medical Sciences, Medical Centre in Pabianice, Lublin University of Technology, Gdansk University of Technology, Regional Military Aviation Medicine Commission in Warsaw, LEKMED Hospital in Warsaw, District Hospital of Orthopedics and Trauma Surgery Piekary Slaskie, Stationary Rehabilitation Centre in Zgorzelec, Medical University of Silesia, Wroclaw Medical University, University of Lausanne (Switzerland), University of Wroclaw, Medical University of Łódź, University of Zielona Góra, University of Rzeszów, Jan Kochanowski University in Kielce Norbert Barlicki University Teaching Hospital No. 1 of the Medical University in Łódź, University of Warsaw, Medical University in Lublin, Jagiellonian University Medical College in Cracow, Cardinal Stefan Wyszyński University in Warsaw, Medical University in Warsaw, St. Barbara Specialist Province Hospital in Sosnowiec, Military Institute of Aviation Medicine in Warsaw, Higher School of Physiotherapy in Wroclaw, Karol Marcinkowski Provincial Clinical Hospital in Zielo- 
na Góra, Hospital for Special Surgery in New York (USA), University of Computer Science and Skills in Lodz, Medical Team of the Polish Football Association, Centre for Orthopedics and Rehabilitation ENEL-SPORT in Warsaw.

The substantive part of the session was opened by the Olympic Session, chaired by Robert Korzeniowski, MA - multiple Olympic champion, world and European champion. Following sessions conducted by eminent specialists concerned: 30 years of anti-doping research in Poland, sport of disabled people, sports and medical certification in Poland, 80 years of sports medicine in Poland (1937-2017), physical activity in the prevention of chronic diseases, regenerative surgery in traumatology and sports orthopaedics, modern diagnostics in sports medicine, physical activity in the prevention of neurodegenerative diseases, modern techniques for treatment of spinal injuries, physical activity in the context of nutrition and diabetes, sports rehabilitation, pro-health sport in the context of physical activity, medicine of sports and travel in old age, genomics, proteomics and biomedicine. There was also a debate on diabetes problems and criteria for returning to physical activity and doing sport after treatment of selected injuries to the locomotor system.

During the poster sessions, the results of research conducted in various areas of sports activity, lifestyle, satisfaction with physical recreation, diagnostic and rehabilitation procedures after injuries resulting from physical activity were presented, with a suggestion of solutions.

The aspect of importance of psychophysical condition for the effective performance of aviation professions was presented by the author team of Zdzisław Kobos from the Department of Psychology, Work and Stress at the Cardinal Stefan Wyszyński University in Warsaw and the Regional Military Aviation and Medical Commission as well as Lt. Col. Rafał Wójcik, M.D., from the Cen- tre for Aviation Medicine of the Military Institute of Aviation Medicine in Warsaw. The presented paper concerned the relationship between physical activity and satisfaction with life among airline pilots and cabin crew. With regard to the aviation professions, the speakers discussed the unfavourable aspects of staying in the aircraft cabin for many hours, in a non-ergonomic position and aspects related to the exposure to G-force or vibration. They emphasized that after many years of working in such non-physiological conditions, various health problems may appear. Therefore physical activity should be a preventive action, carried out through targeted training during the time spent outside the cockpit.

The Congress showed the multidisciplinarity of research and activity of the interdisciplinary environment dealing with sport, physical recreation and individual physical activity.

To sum up, it should be emphasized that the reports presented during the Congress by the researchers covered a very wide range of issues of physical activity, competitive as well as amateur and recreational. During the three-day debate, 17 thematic sessions were conducted, during which 64 papers were delivered, 18 research-describing posters were presented and 5 workshops were conducted.

Our participation in the Congress allowed us to become acquainted with interesting research of specialists from many disciplines of knowledge dealing with physical activity and its evaluation for the purposes of judicial decisions and opened new areas of cooperation in the field of maintaining and improving the psychophysical condition of aviation personnel. Substantive contacts were also established in the field of rehabilitation and biological regeneration, as well as scientific cooperation in conducting medical and psychological examinations during specialist trainings and procedures during treatment and fitness camps. 